\title{
Maize Processing Waste Water Upcycling in Mexico: Recovery of Arabinoxylans for Probiotic Encapsulation
}

\author{
Rita Paz-Samaniego ${ }^{1}$, Elizabeth Carvajal-Millan ${ }^{1, *}$, Norberto Sotelo-Cruz ${ }^{2}$, Francisco Brown ${ }^{3}$, \\ Agustín Rascón-Chu ${ }^{1}$, Yolanda L. López-Franco ${ }^{1}$ and Jaime Lizardi-Mendoza ${ }^{1}$ \\ 1 Research Center for Food and Development, CIAD, A.C. 83304 Hermosillo, Sonora, Mexico; \\ rpaz@estudiantes.ciad.mx (R.P.-S.); arascon@ciad.mx (A.R.-C.); lopezf@ciad.mx (Y.L.L.-F.); \\ jalim@ciad.mx (J.L.-M.) \\ 2 Department of Medicine, University of Sonora, 83000 Hermosillo, Sonora, Mexico; \\ norberto.sotelo@unison.mx \\ 3 Department of Polymers and Materials, University of Sonora, 83000 Hermosillo, Sonora, Mexico; \\ fbrown@guaymas.uson.mx \\ * Correspondence: ecarvajal@ciad.mx; Tel.: +52-662-289-2400; Fax: +52-662-280-0421
}

Academic Editor: Thomas A. Trabold

Received: 9 August 2016; Accepted: 18 October 2016; Published: 1 November 2016

\begin{abstract}
Maize is a major source of food in Mexico. In order to improve its nutritional value, maize kernel is exposed to an alkali treatment that generates large volumes of waste water containing gelling arabinoxylan. The purpose of the present study was to evaluate the capability of maize waste water arabinoxylans (MWAX) to encapsulate probiotics. The rheological, structural, and microstructural characteristics of this bio-based material were also investigated. MWAX gels at $10 \%(\mathrm{w} / \mathrm{v})$ were able to encapsulate Bifidobacterium as probiotic model. The MWAX gel containing $1 \times 10^{7} \mathrm{CFU} / \mathrm{mL}$ of probiotics presented a storage $\left(\mathrm{G}^{\prime}\right)$ and loss $\left(\mathrm{G}^{\prime \prime}\right)$ moduli of 50 and $11 \mathrm{~Pa}$, respectively. The average mesh size of the MWAX gel was around 11 times smaller than the Bifidobacterium cell magnitude. MWAX gels with or without probiotics were studied using scanning electron microscopy. The interior of the Bifidobacterium loaded gels was composed of a pore-like network of MWAX through which probiotics were distributed. The probiotic encapsulating MWAX gels appeared to be less porous than the empty gels. MWAX capability to encapsulate Bifidobacterium may be important in designing probiotic encapsulating biodegradable gels and could represent an opportunity in sustainable food waste management and utilization through upcycling to value-added products.
\end{abstract}

Keywords: waste water; food industry; polysaccharide; gels; value-added products

\section{Introduction}

In the past, Mesoamerican Indians learned that wood ashes facilitated maize cooking, the removal of the hard outer covering, and improved the quality of the resulting material. We now know that this process also releases the bound niacin in the maize into a readily available form [1], preventing the population from suffering the ravages of pellagra. In Mexico, alkali cooking called "nixtamalization" (from the Nahuatl nixtli = ashes and tamalli = dough) is extensively used to improve maize texture and nutritional value [2]. Maize nixtamalization is important in Mexico, as half of the total volume of consumed food is maize, which provides approximately $50 \%$ of the energy intake, this proportion being even greater for lower income groups. The waste water generated from this maize processing is called "Nejayote" which is highly alkaline, with high chemical and biological oxygen demands, and is considered an environmental pollutant. A typical maize nixtamalization facility processing $50 \mathrm{~kg}$ of maize every day uses over $75 \mathrm{~L}$ of water per day and generates nearly the equivalent amount of 
alkaline waste water in $24 \mathrm{~h}$ [3]. Thus, alternatives of maize alkaline waste water utilization in Mexico are needed. During the nixtamalization process, maize bran is removed from the kernel, and some of the cell wall components such as arabinoxylans are partially solubilized in Nejayote. In fact, Nejayote has been previously reported as a source of gelling arabinoxylans [2-4].

Arabinoxylans (AX) are the main non-starch polysaccharides of cereal grains. AX consist of a linear chain of $\beta$-( $1 \rightarrow 4)$-linked xylose units, to which $\alpha$-L-arabinose substituents are attached through O-2, O-3, or both. Arabinose residues can be linked on O-5 to ferulic acid (FA) (3-methoxy-4-hydroxycinnamic acid) via esterification [5,6] (Figure 1). Several investigations have reported the positive health effects of AX due to their antioxidant and prebiotic properties as well as their immune-enhancing ability and anti-tumoral activity [7,8]. In addition, AX can form covalent gels by the oxidative coupling of FA, resulting in the formation of dimers (di-FA) and a trimer (tri-FA) as covalent cross-linking structures [9]. The stability of the AX gels to changes in temperature, $\mathrm{pH}$, and ionic strength offers an advantage for the industrial applications of this polysaccharide. A previous study has demonstrated that AX gels can be used for the entrapment of probiotics [10,11]. However, that investigation used water extractable AX from wheat flour as a model molecule due the less complex structure of this polysaccharide in comparison to water un-extractable $\mathrm{AX}$ from cereal brans. In this regard, maize bran is a richer and cheaper source of this polysaccharide, especially when AX are recovered from by-products of the food industry, which has received increasing attention and would offer new advantages for future industrial applications of this polysaccharide. However, to our knowledge, the probiotic loading capability of gelling maize wastewater arabinoxylans (MWAX) has not been reported. The objective of the present study was to investigate the capability of MWAX to encapsulate probiotics and to investigate the rheological and microstructural characteristics of the bio-based material formed.

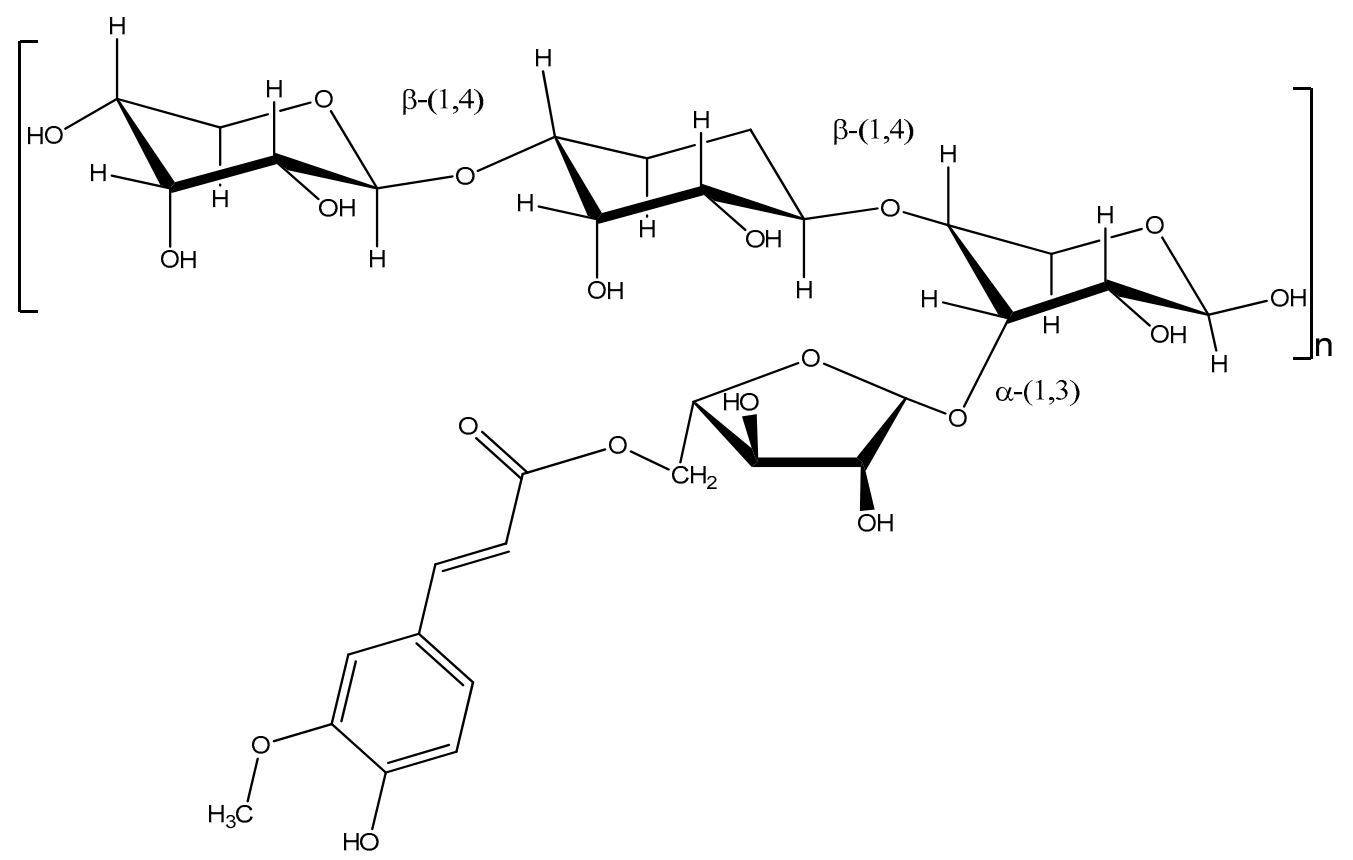

Figure 1. General chemical structure of ferulated arabinoxylans (AX).

\section{Materials and Methods}

\subsection{Materials}

Nejayote was kindly provided by a tortilla-making factory in Northern Mexico. Chemical products and laccase (benzenediol:oxygen oxidoreductase, E.C.1.10.3.2) from Trametes versicolor were acquired from Sigma Co. (St. Louis, MO, USA). 


\subsection{Strains and Culture Conditions}

Bifidobacterium longum ATCC 15708 and Bifidobacterium adolescentis ATCC 15703 were obtained from the American Type Culture Collection (ATCC; Manasas, VA, USA). Bacteria were kept at $-80{ }^{\circ} \mathrm{C}$ in glycerol stock solutions. The bacterial suspensions were thawed, and the bacteria were reactivated in De Man-Rogosa-Sharpe (MRS) broth with 0.05\% L-cysteine hydrochloride for $24 \mathrm{~h}$ at $37^{\circ} \mathrm{C}$ and subcultured in Bifidus selective medium (BSM) broth for $24 \mathrm{~h}$ at $37^{\circ} \mathrm{C}$. All cultures were incubated under anaerobic conditions using an anaerobic GasPak ${ }^{\circledR}$ jar containing a generator envelope (Oxoid Ltd., Basingtoke, UK) [12]. In addition, $100 \mu \mathrm{L}$ of Oxyrase (Oxyrase Inc., Mansfield, OH, USA) were added to the broth to remove oxygen from the microenvironment [13]. Bacterial biomass was harvested via centrifugation at $2000 \mathrm{~g}$ for $10 \mathrm{~min}$ at $4{ }^{\circ} \mathrm{C}$, washed twice in a sterile saline solution $(\mathrm{NaCl}$ $0.85 \% \mathrm{w} / \mathrm{v}$ ) under the same centrifugation conditions, and resuspended in $1 \mathrm{~mL}$ of a sterile saline solution $[12,13]$. These suspensions were incorporated in MWAX solutions and homogenized, and the gel was then prepared as previously reported [11].

\subsection{Methods}

\subsubsection{MWAX Extraction and Chemical Composition}

MWAX were extracted as described in a previously reported patent [14]. The neutral sugar content in MWAX was determined by high-performance liquid chromatography (HPLC) according to the methodology previously reported [15]. The hydrolysis was performed with $2 \mathrm{~N}$ trifluoroacetic acid at $120^{\circ} \mathrm{C}$ for $2 \mathrm{~h}$; then, the reaction was stopped on ice. The extracts were evaporated at $40{ }^{\circ} \mathrm{C}$ with an air flow and washed twice with $200 \mu \mathrm{L}$ of water. The evaporated extract was dissolved in $500 \mu \mathrm{L}$ of water and passed through a $0.2 \mu \mathrm{m}$ filter (Whatman). Mannitol was used as an internal standard. HPLC analyses were performed using a Varian 9012 HPLC with a Supelcogel Pb column ( $300 \times 7.8 \mathrm{~mm}$; Supelco, Inc., Bellefont, PA, USA) and were eluted with $5 \mathrm{mM} \mathrm{H}_{2} \mathrm{SO}_{4}$ at $0.6 \mathrm{~mL} / \mathrm{min}$ and at $50{ }^{\circ} \mathrm{C}$. A Varian 9040 refractive index detector (Varian, St. Helens, Australia) and a Star Chromatography Workstation system control version 5.50 were used. The protein content in MWAX was determined according to the Bradford method [16]. The ash content was determined as described by the AOAC methods [17]. The ferulic acid (FA) content in MWAX was determined by reverse phase high-performance liquid chromatography (RP-HPLC) after a de-esterification step, as previously described [2]. A Waters 996 (Millipore Co., Milford, MA, USA) photodiode array detector and an Alltima C18 column $(250 \times 4.6 \mathrm{~mm}$; Alltech Associates, Inc., Deerfield, IL, USA) were used. Detection was followed by measuring the UV absorbance at $320 \mathrm{~nm}$. The measurements were performed in triplicate.

\subsubsection{Gel Preparation and Probiotics Inclusion}

A $10 \%$ MWAX solution ( $\mathrm{w} / \mathrm{v}$ ) was prepared in a $0.1 \mathrm{M}$ sodium acetate buffer, $\mathrm{pH}$ 5.5. B. longum and B. adolescentis $\left(1 \times 10^{7} \mathrm{CFU} / \mathrm{mL}\right)$ were each suspended in the $10 \%$ MWAX solution, and laccase (1.675 nkat/mg MWAX) served as a cross-linking agent [11]. Gels were allowed to set for $4 \mathrm{~h}$ at $25^{\circ} \mathrm{C}$. All MWAX gels, with and without probiotics, were prepared under aseptic conditions.

\subsubsection{Rheology}

The formation of MWAX gels with or without bacteria was rheologically investigated by a small amplitude oscillatory shear. A MWAX solution (10\% w/v) and an MWAX solution (10\% w/v) with bacteria $\left(1 \times 10^{7} \mathrm{CFU} / \mathrm{mL}\right)$ in sodium acetate of $0.1 \mathrm{M}$ were mixed with laccase and immediately placed in the parallel plate geometry (with a diameter of $4.0 \mathrm{~cm}$ ) of a strain controller rheometer (Discovery HR-2 rheometer; TA Instruments, New Castle, DE, USA). Exposed edges were covered with silicone to prevent water loss. The rheological parameters used to evaluate gel hardness were the storage modulus $\left(G^{\prime}\right)$, loss modulus $\left(G^{\prime \prime}\right)$, $\tan \delta\left(G^{\prime \prime} / G^{\prime}\right)$, and crossover point $\left(G^{\prime}>G^{\prime \prime}\right)$ or gelation time. MWAX gelation was monitored at $25^{\circ} \mathrm{C}$ for $4 \mathrm{~h}$. All measurements were realized at $25^{\circ} \mathrm{C}$, a frequency 
of $0.25 \mathrm{~Hz}$ and $5 \%$ strain [2]. After the end of network formation, a frequency sweep $(0.01-10 \mathrm{~Hz})$ was carried out. The rheological tests were performed in duplicate, and the results were reported as the means.

\subsubsection{Swelling}

After laccase addition, two milliliters of MWAX solutions $(10 \% \mathrm{w} / \mathrm{v})$ were quickly transferred to a tip-cut-off syringe (diameter $1.5 \mathrm{~cm}$ ) and left to stand until gelation for $18 \mathrm{~h}$ at $26^{\circ} \mathrm{C}$. When gelation was complete, the gels were removed from the syringes, placed in glass vials and weighted. The gels were swollen at $26{ }^{\circ} \mathrm{C}$ in $20 \mathrm{~mL}$ of a sodium azide $0.02 \%(\mathrm{w} / \mathrm{v})$ solution to prevent microbial contamination. Gels were removed from the sodium azide solution, and the excess of liquid was discarded. Once weighed, a new aliquot of the antimicrobial solution was added. The gels were weighed every hour for $24 \mathrm{~h}$ until the weight of the samples did not vary by more than $3 \%(0.06 \mathrm{~g})$ and the equilibrium swelling was reached. The swelling ratio, $\mathrm{q}$, was calculated by the following equation:

$$
\mathrm{q}=\left(\mathrm{Ws}-\mathrm{W}_{\mathrm{MWAX}}\right) / \mathrm{W}_{\mathrm{MWAX}}
$$

where Ws is the weight of swollen gels, and $\mathrm{W}_{\text {MWAX }}$ is the weight of MWAX in the gel. The MWAX weight in the gel was calculated by taking into account the AX in the MWAX solution $(10 \% \mathrm{w} / \mathrm{v})$ and the fresh weight of the gel after removal from the syringe [9].

\subsubsection{Structural Parameters}

The structural parameters of the MWAX gel were calculated from swelling measurements as reported previously [9]. The molecular weight between two cross-links (Mc) was calculated using the model of Flory and Rehner [18] adapted by Peppas and Merrill (Equation (2)) [19].

$$
\frac{1}{\mathrm{Mc}}=\frac{2}{\mathrm{Mn}}-\frac{\left(\frac{v}{V_{1}}\right)-\left[\ln \left(1-v_{2, s}\right)+v_{2, s}+\chi^{1}\left(v_{2, s}\right)^{2}\right]}{v_{2, r}\left[\left(\frac{v_{2, s}}{v_{2, r}}\right)^{\frac{1}{3}}-\frac{1}{2}\left(\frac{v_{2, s}}{v_{2, r}}\right)\right]},
$$

where Mn is the number average molecular weight of $\operatorname{MWAX}(135,000 \mathrm{~g} / \mathrm{mol}$, considering only the xylose backbone). In Equation (2), $V_{1}$ is the molar volume of water $\left(18 \mathrm{~cm}^{3} / \mathrm{g}\right), v_{2, r}$ and $v_{2, s}$ are the polymer volume fractions of the gel in a relaxed state (directly after gel formation) and at equilibrium swelling, respectively. $\chi^{1}$ is the Flory polymer-solvent interaction parameter (0.5). The partial specific volume $(v)$ of MWAX was $0.0703 \mathrm{~cm}^{3} / \mathrm{g}$.

From the Mc values, the average mesh size $(\xi)$ and the cross-linking density $\left(\varrho_{c}\right)$ in the MWAX gels were calculated as previously reported [9] (Equations (3) and (4)).

$$
\begin{gathered}
\xi=v_{2, s}{ }^{-1 / 3}\left(\frac{2 \mathrm{CnMc}}{\mathrm{Mr}}\right)^{1 / 2} l, \text { and } \\
\varrho_{\mathrm{c}}=\frac{1}{v \mathrm{Mc}},
\end{gathered}
$$

with $\mathrm{Mr}$ representing the molecular weight of the repeating unit (xylose, $132 \mathrm{~g} / \mathrm{mol}$ ), Cn the characteristic ratio for AX (11.5), and l the bond length between two xyloses $(0.286 \mathrm{~nm})$ [9].

\subsubsection{Scanning Electron Microscopy}

The MWAX gels at $10 \%(\mathrm{w} / \mathrm{v})$ and MWAX gels containing probiotics were frozen at $-20{ }^{\circ} \mathrm{C}$ and lyophilized at $-40^{\circ} \mathrm{C} / 0.133$ mbar (Freezone 6 freeze dryer, Labconco, Kansas City, MO, USA). The microstructures of the freeze-dried MWAX gels were studied by scanning electron microscopy (SEM) without coating at low voltage $(1.8 \mathrm{kV})$ using a JEOL JSM-7401F (Peabody, MA, USA). SEM images were obtained by secondary and backscattered electrons [11]. 


\subsubsection{Statistical Analysis}

Chemical determinations were made in triplicate, and the coefficients of variation were lower than $5 \%$. Small deformation measurements were made in duplicate, and the experiments of swelling was realized by triplicate, and both coefficients of variation were lower than $5 \%$. Results are expressed as the mean values.

\section{Results and Discussion}

\subsection{Yield and Chemical Composition}

The extraction of MWAX is represented in Figure 2. MWAX consisted of a fine white powder with some granulated parts similar in appearance to other AX reported in the literature $[5,20]$. The yield of MWAX was $0.90 \%$ (dry weight of polysaccharide/volume of waste water), which is higher than the value reported for water extractable AX used to entrap probiotics in a previous report (0.45-0.50 dry weight of polysaccharide/dry weight of wheat flour) [21]. Considering the total dispersed solids present in the maize processing waste water the yield of MWAX was $46 \%$ (dry weight of polysaccharide/dry weight of solids).
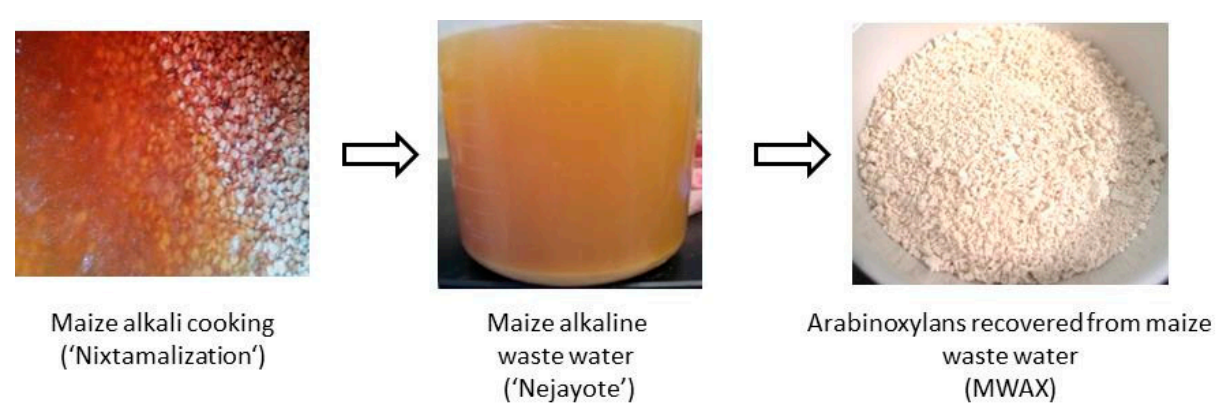

Figure 2. Recovery of maize wastewater arabinoxylans (MWAX) from alkaline maize waste water.

In addition, extraction of water extractable AX from wheat flour involves the use of hydrolytic enzymes to eliminate proteins and starch from the extract, which increase the process cost. In this regard, extraction of AX from food industry by-products such as maize alkaline wastewater would offer advantages for future industrial applications of this polysaccharide. It is important to note that the polysaccharide yield found in the present study was lower than the value reported for other MWAX $(8 \% \mathrm{w} / \mathrm{v}$ volume of waste water) [2]. This difference could be due to differences in the nixtamalization process used in this study, as it remains an artisan process in small tortilla-making factories. In previous studies [2,14], maize kernels were lime-cooked for $1 \mathrm{~h}$ and stored at $25^{\circ} \mathrm{C}$ for $12 \mathrm{~h}$; in the present study, maize was lime-cooked for $1.5 \mathrm{~h}$ and maintained at $25^{\circ} \mathrm{C}$ for $24 \mathrm{~h}$. A longer alkaline exposure of maize could result in an extensive hydrolysis of the cell wall components generating larger amounts of low molecular weight $\mathrm{AX}$, which may not precipitate in ethanol during the extraction procedure.

The chemical composition of MWAX is presented in Table 1 . AX represented $66 \%$ dry basis $(\mathrm{db})$ of the sample. This result was calculated from the sum of xylose and arabinose. The arabinose to xylose ratio $(\mathrm{A} / \mathrm{X})$ was high (0.85), indicating a highly branched structure. Depending on the source of $\mathrm{AX}$, the $\mathrm{A} / \mathrm{X}$ value can fluctuate from 0.3 to 1.1 being lower in endosperm than in bran grain [5]. Arabinose residues increase the hydrophilic character of the polysaccharide, which could explain the high water solubility of MWAX found in the present study, allowing the formation of MWAX solutions at $10 \%(\mathrm{w} / \mathrm{v})$. Izydorczyk and Biliaderis [5] indicated that the chain of xylose unsubstituided or low-substituted with arabinose aggregates into insoluble complexes stabilized by intermolecular H-bonding, which limits water solubility. The presence of arabinose restricts the aggregation of AX molecules by steric hindrance [5,20]. Niño-Medina et al. [2] reported a moderately branched structure $(A / X=0.65)$ for MWAX and a maximal concentration of just $8 \%(w / v)$ of MWAX in water. 
Small amounts of glucose, galactose, protein, and minerals (ashes) were also detected in MWAX, similarly to previous reports on other maize AX [2-4]. The FA content in MWAX was $0.012 \pm 0.001$ ( $\mu \mathrm{g} / \mathrm{mg}$ polysaccharide), which is smaller than the value reported for other MWAX $(0.23 \mu \mathrm{g} / \mathrm{mg}$ polysaccharide). This result could also be attributed to the extended alkaline exposure of maize kernels used in the present study, since alkaline conditions can de-esterify FA from the arabinose residues along the polysaccharide chains $[2,22]$.

Table 1. Composition of MWAX.

\begin{tabular}{cc}
\hline Component & Value \\
\hline Arabinose & $30.2 \pm 0.195$ \\
Xylose & $35.4 \pm 0.053$ \\
Galactose & $12.8 \pm 0.356$ \\
Glucose & $1.66 \pm 0.014$ \\
Protein & $1.59 \pm 0.13$ \\
Ash & $1.48 \pm 0.029$ \\
Ferulic acid & $0.012 \pm 0.001$ \\
\hline
\end{tabular}

Data are expressed in $\mathrm{g} / 100 \mathrm{~g}$ MWAX dry matter. FA is expressed in $\mu \mathrm{g} / \mathrm{mg}$ of MWAX. Values are the mean \pm standard deviation. All results are obtained from triplicate measurements.

\subsection{Gelation}

The gelation kinetics of MWAX solutions $(10 \% \mathrm{w} / \mathrm{v})$ were studied using small deformation rheology. The rapid increase in elastic modulus $\left(G^{\prime}\right)$ and viscous modulus $\left(G^{\prime \prime}\right)$ at the start of the reaction followed by a region of stability indicates the rapid formation of covalent bonds between the FA of neighboring chains of MWAX producing a cross-linked polymer network (Figure 3). When sufficient cross-links have been formed, the movement of chains is impeded by the rigidity of the polymeric network [11]. Similar profiles have been previously reported for AX gels cross-linked by laccase or peroxidase $/ \mathrm{H}_{2} \mathrm{O}_{2}$ systems [22-24]. Niño-Medina et al. [25] reported MWAX gels at $4 \%$ and $8 \%(\mathrm{w} / \mathrm{v})$ with a smaller $\mathrm{G}^{\prime}(2$ and $4 \mathrm{~Pa}$, respectively) and a higher crossover point of $150 \mathrm{~min}$. On the other hand, Ayala-Soto et al. [4] reported MWAX gels at $4 \%(\mathrm{w} / \mathrm{v})$, which showed a fluid behavior with a $G^{\prime}$ value smaller that $G^{\prime \prime}$. These differences could be due to the structural and/or conformational characteristics of each macromolecule [25] and to the specific conditions of the rheological experiments. It is possible that the features of MWAX found in the present study (higher molecular weight and $\mathrm{A} / \mathrm{X}$ values) and the concentration used $(10 \% \mathrm{w} / \mathrm{v})$ promoted the cross-linking of chains allowing the formation of a more elastic gel $(76 \mathrm{~Pa})$. Additional studies of the distributions of arabinose and feruloyl groups along the polymer chain backbone are required to establish relationships between the MWAX molecular structure and the gelling ability as well as gel properties.

The addition of probiotics to the MWAX solution decreased the elasticity of the gel by $34 \%$ after $4 \mathrm{~h}$ of laccase action (Figure 3). The $\mathrm{G}^{\prime \prime}$ value of the gel was not affected by the presence of Bifidobacterium (11 Pa). The tan $\delta$ value (calculated at the end of the test at $0.25 \mathrm{~Hz}$ ) was smaller than for the MWAX solution without bacteria (0.22), indicating the presence of a less elastic covalent system. The slight increase in the $\tan \delta$ value in the MWAX gel that contains probiotics indicates a higher viscous contribution to the network, which could be related to an increase in the polymer chain flexibility in the gel. The presence of probiotics could affect physical interactions between MWAX chains, which would affect network connectivity [10,11].

The mechanical spectra of MWAX gels and MWAX gels containing Bifidobacterium exhibited a solid-like behavior with $G^{\prime}>G^{\prime \prime}$ (Figure 4). This behavior of AX gels with a linear $G^{\prime}$ independent of frequency as well as a $G^{\prime \prime}$ much smaller than $G^{\prime}$ and dependent on the frequency has been previously reported [9]. The frequency sweep of both gels showed that $\mathrm{G}^{\prime}$ slightly increased after $0.5 \mathrm{~Hz}$, which may be due to the presence of non-covalent interactions in the polymer network in addition to the covalent bonds induced by laccase, as previously suggested $[9,21]$. The presence of probiotic bacteria affected the polymer chain interactions, as indicated by $\mathrm{G}^{\prime}, \mathrm{G}^{\prime \prime}$, and $\tan \delta$; nevertheless, the frequency scan indicated an acceptable stability of the system. 


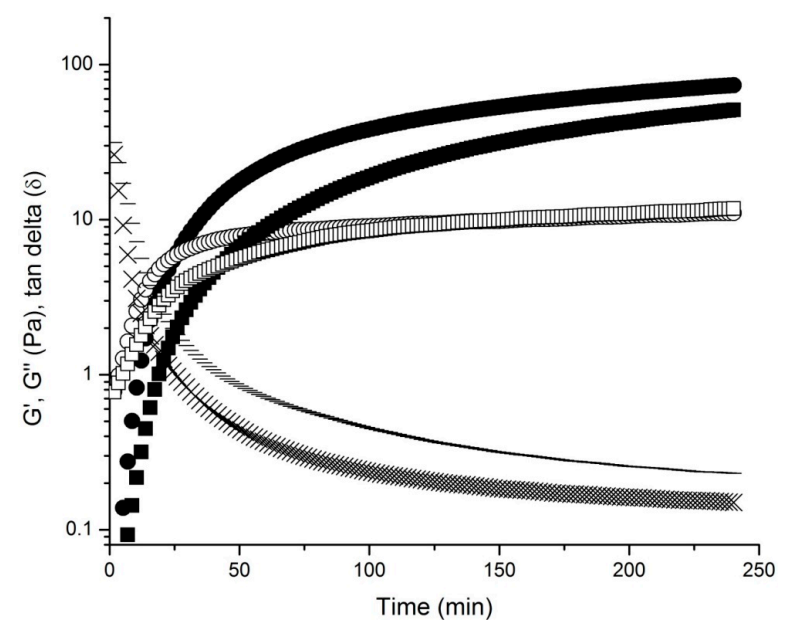

Figure 3. Monitoring elastic modulus $\left(G^{\prime}\right)$, viscous modulus $\left(G^{\prime \prime}\right)$, and tangent delta $\left(\tan \delta, G^{\prime \prime} / G^{\prime}\right)$ during rheological kinetics of $10 \%(\mathrm{w} / \mathrm{v})$ MWAX solution gelation without probiotics $\left(\mathrm{G}^{\prime} \bullet \mathrm{G}^{\prime \prime} \bigcirc\right.$, and $\tan \delta \mathrm{x})$ and containing Bifidobacterium $\left(1 \times 10^{7} \mathrm{CFU} / \mathrm{mL}\right)\left(\mathrm{G}^{\prime} \mathbf{\square}, \mathrm{G}^{\prime \prime} \square\right.$, and $\tan \delta$-). Laccase was used as cross-linking agent. Rheological measurements at $25^{\circ} \mathrm{C}, 0.25 \mathrm{~Hz}$, and $5 \%$ strain.

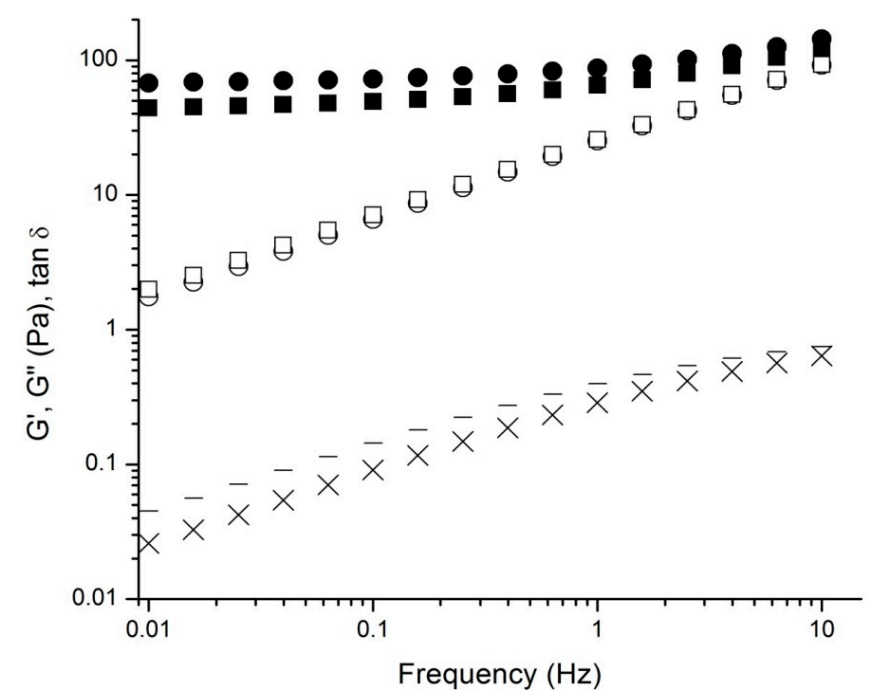

Figure 4. Mechanical spectrum of $10 \%(\mathrm{w} / \mathrm{v}) \operatorname{MWAX}$ gel $\left(\mathrm{G}^{\prime} \bullet, \mathrm{G}^{\prime \prime} \bigcirc\right.$, and $\left.\tan \delta \mathrm{x}\right)$ and $10 \%(\mathrm{w} / \mathrm{v})$ MWAX gel containing Bifidobacterium $\left(1 \times 10^{7} \mathrm{CFU} / \mathrm{mL}\right)\left(\mathrm{G}^{\prime} \mathbf{\square}, \mathrm{G}^{\prime \prime} \square\right.$, and $\left.\tan \delta-\right)$. $\mathrm{G}^{\prime}$ is the elastic modulus, $G^{\prime \prime}$ is the viscous modulus, and $\tan \delta$ is the tangent delta $\left(G^{\prime \prime} / G^{\prime}\right)$. Rheological measurements at $25{ }^{\circ} \mathrm{C}$ and $5 \%$ strain.

\subsection{Structural Parameters}

The structural parameters molecular weight between two point cross-links (Mc), cross-linking density $\left(\varrho_{\mathrm{c}}\right)$ and average mesh size $(\xi)$ in MWAX gels, were calculated from the swelling experiments as reported previously [9]. The equilibrium swelling of MWAX gels at $10 \%(\mathrm{w} / \mathrm{v})$ was reached between 15 and $20 \mathrm{~h}$ presenting a swelling ratio ( $\mathrm{q}, \mathrm{g}$ water/g polymer) value of $49 \mathrm{~g}$ water/g MWAX. The swelling capacity of a gel is directly related to the chemical structure and conformation of the polymer as well as the degree of cross-linking of the polymer network [22,23]. In addition, the q value is a measurement inversely proportional to the strength of the polymer gel, where higher q values represent a weak polymeric gel structure with high water absorption. The Mc, $\varrho_{c}$, and $\xi$ value of the MWAX gel found in the present study are reported in Table 2. The q, Mc, $\varrho_{c}$, and $\xi$ values found were similar to those reported for other maize AX gels using peroxidase $/ \mathrm{H}_{2} \mathrm{O}_{2}$ or laccase as cross-linking 
agent [24]. It has been reported that the characteristic rod or clubbed shape of Bifidobacterium varies from $0.5-1.3 \mu \mathrm{m} \times 1.5-8 \mu \mathrm{m}$ [26], which is around 11 times higher than the $\xi$ value $(413 \mathrm{~nm})$ found for MWAX gels in the present study (Figure 5). This mesh size/bacteria dimensions ratio could explain the MWAX capability to encapsulate Bifidobacterium and may protect the contained cell during food processing or gastric conditions. In Figure 6 a section of the MWAX polymer network containing Bifidobacterium is shown.

Table 2. Structural parameters of $10 \%(\mathrm{w} / \mathrm{v})$ MWAX gel.

\begin{tabular}{cc}
\hline Parameter & Value \\
\hline $\begin{array}{c}\text { Molecular weight between two cross-links, } \\
\text { Mc } \times 10^{3}(\mathrm{~g} / \mathrm{mol})\end{array}$ & $67 \pm 0.1$ \\
\hline $\begin{array}{c}\text { Cross-linking density, } \\
\varrho_{\mathrm{c}} \times 10^{-4}\left(\mathrm{~mol} / \mathrm{cm}^{3}\right)\end{array}$ & $2.11 \pm 0.01$ \\
\hline $\begin{array}{c}\text { Mesh size, } \\
\xi(\mathrm{nm})\end{array}$ & $413 \pm 6$ \\
\hline
\end{tabular}

All values are means \pm standard deviation of three repetitions.

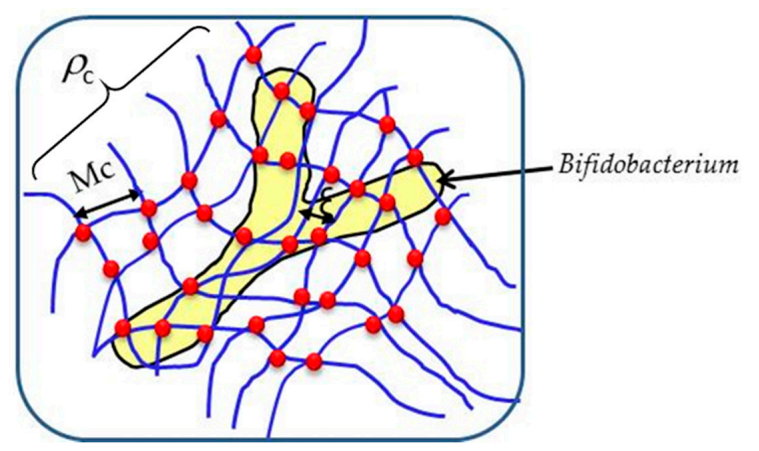

Figure 5. Representation of MWAX polymer network section containing Bifidobacterium.

\subsection{Microscopy}

Figure 6 shows MWAX gels and MWAX gels containing Bifidobacterium images before (Figure 6a,c) and after freeze drying (Figure $6 \mathrm{~b}$,d). It has been reported that frozen caused the crust formation of the gel [10]. The microstructural characteristics of lyophilized MWAX gel and MWAX gel containing Bifidobacterium were analyzed via scanning electron microscopy (SEM) (Figure 7). A marked difference in the microstructure of probiotic encapsulating and non-encapsulating MWAX gels was observed. MWAX gel shows a heterogeneous microstructure resembling an irregular honeycomb, similar to that reported for other maize AX gels (Figure 7a,b). The SEM image of lyophilized MWAX gel containing probiotics shows a mesh-like network through which bacteria are distributed. The micron-sized structures corresponding to Bifidobacteria are indicated in Figure $7 \mathrm{~b}$. In the present study, the incorporation of probiotics into the gels was performed under aseptic conditions. Therefore, the only bacteria observed in scanning electron microscopy are B. longum and B. adolescentis, which come from the reference ATCC cultures used; besides, typical morphology, sizes, and shapes are in agreement with those reported in the literature [26,27].

Bacteria-encapsulating gels appeared to be less porous and present a more homogeneous microstructure than the empty gels (Figure 7c,d). A similar WEAX gel microstructure preservation was reported for Bifidobacterium longum entrapped in water extractable AX gels [11]. It has been reported that some bacteria produce extracellular polymeric substances that can inhibit ice recrystallization and protect from low temperature. However, to our knowledge, this kind of behavior has not been reported for Bifidobacterium, and complementary research is needed to elucidate the mechanism 
of AX gel microstructure preservation by this bacteria. In this regard, it has been suggested that Bifidobacterium interacts with polysaccharides such as AX and starch, forming biofilms via bacteria cell surface protein complexes, which include binding proteins and hydrolyzing enzymes [28,29]. The interaction Bifidobacteria-AX could be present in the MWAX gel, contributing to the preservation of the gel microstructure. Nevertheless, the evidence reported herein is not sufficient to confirm it.

On the other hand, the lower porosity of Bifidobacterium-loaded MWAX gel may be an advantage, as a less porous matrix is more protective to the bacteria. It is important to note that the microstructures observed in a lyophilized gel may be different from those existing in the hydrated gel as three-dimensional structures might be distorted; however, lyophilization allows for the obtainment of fine images of meshwork microstructures.
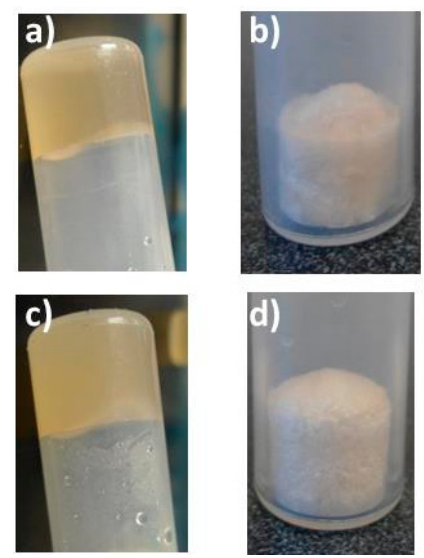

Figure 6. MWAX gels $(\mathbf{a}, \mathbf{b})$ and MWAX gels containing Bifidobacterium $\left(1 \times 10^{7} \mathrm{CFU} / \mathrm{mL}\right)(\mathbf{c}, \mathbf{d})$ before $(\mathbf{a}, \mathbf{c})$ and after $(\mathbf{b}, \mathbf{d})$ lyophylization.
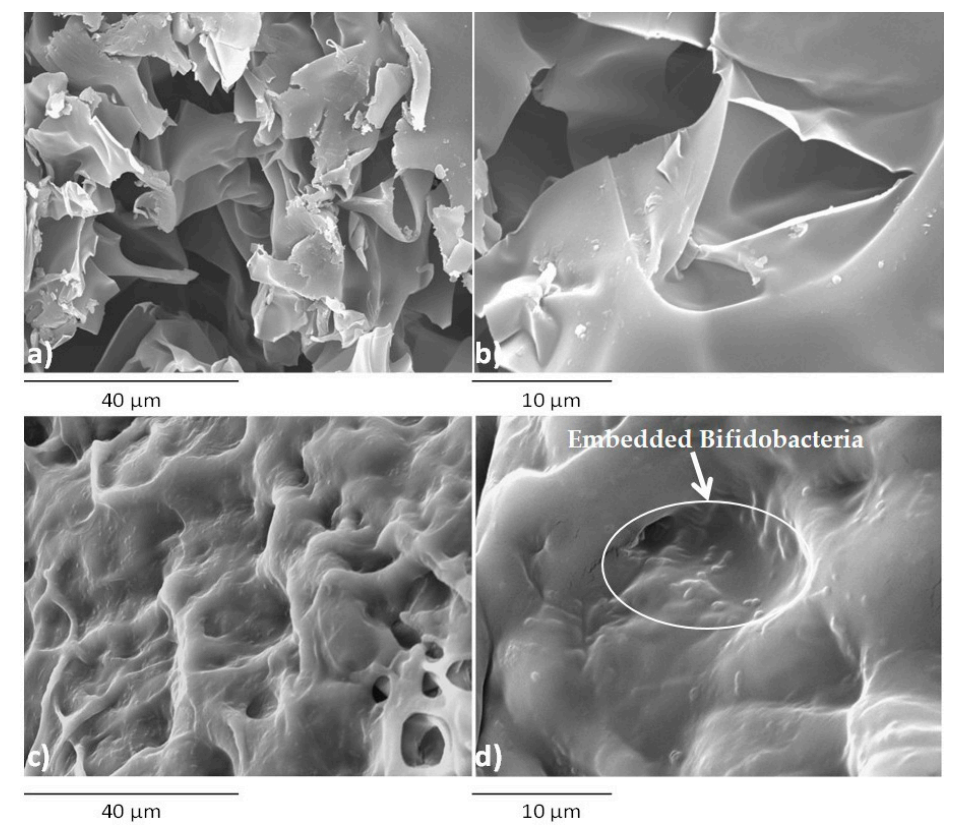

Figure 7. Scanning electron microscopy of lyophilized MWAX gels $(\mathbf{a}, \mathbf{b})$ and MWAX gels containing Bifidobacteria (c,d). Images $(\mathbf{a})$ and $(\mathbf{c})$ at $1500 \times ;(\mathbf{b})$ and $(\mathbf{d})$ at $3500 \times$.

\section{Conclusions}

Gelling MWAX are able to encapsulate Bifidobacterium. Under the conditions used in the present study, the presence of $1 \times 10^{7} \mathrm{CFU} / \mathrm{mL}$ decreased the gel elasticity by $34 \%$. The average mesh size of 
the MWAX gel is around 11 times smaller than the Bifidobacterium magnitude reported in the literature, and this may protect the encapsulated cells. The Bifidobacterium-loaded MWAX gel microstructure shows a pore-like network through which bacteria are distributed. The probiotic-encapsulating MWAX gels appeared to be less porous than the non-loaded gels. The capability of MWAX to encapsulate Bifidobacterium may be useful for the development and production of food or food ingredients containing probiotics. In this regard, MWAX may represent an opportunity in sustainable food waste management and utilization through the upcycling to value-added products.

Acknowledgments: This research was supported by “Fondo Institucional CONACyT-Investigación en Fronteras de la Ciencia", Mexico (Grant FON.INST./31/2016 to E. Carvajal-Millan). The authors are pleased to acknowledge Alma C. Campa-Mada and Karla G. Martínez-Robinson (CIAD) for their technical assistance.

Author Contributions: Rita Paz-Samaniego performed the experiments, analyzed the data, and wrote the paper draft. Elizabeth Carvajal-Millan conceived and designed the experiments, contributed to the discussion of the results, and edited the paper. Francisco Brown-Bojorquez performed the SEM analysis and contributed to the discussion of the results. Agustín Rascón-Chu, Norberto Sotelo-Cruz, Yolanda L. López-Franco, and Jaime Lizardi-Mendoza contributed to the discussion of the results and the editing of the paper.

Conflicts of Interest: The authors declare no conflict of interest.

\section{References}

1. Kent, N.L.; Evers, A.D. Technology of Cereals: An Introduction for Students of Food Science and Agriculture, 4th ed.; Elsevier Science Ltd.: Oxford, UK, 1994.

2. Niño-Medina, G.; Carvajal-Millán, E.; Lizardi, J.; Rascon-Chu, A.; Marquez-Escalante, J.A.; Gardea, A.; Martinez-Lopez, A.L.; Guerrero, V. Maize processing waste water arabinoxylans: Gelling capability and cross-linking content. Food Chem. 2009, 115, 1286-1290. [CrossRef]

3. Paz-Samaniego, R.; Carvajal-Millan, E.; Brown-Bojorquez, F.; Rascón-Chu, A.; López-Franco, Y.L.; Sotelo-Cruz, N.; Lizardi-Mendoza, J. Gelation of arabinoxylans from maize wastewater-Effect of alkaline hydrolysis conditions on the gel rheology and microstructure. In Wastewater Treatment Engineering; Samer, M., Ed.; InTech: Rijeka, Croatia, 2015; pp. 101-114.

4. Ayala-Soto, F.E.; Serna-Saldívar, S.O.; Pérez-Carrillo, E.; García-Lara, S. Relationship between hydroxycinnamic profile with gelation capacity and rheological properties of arabinoxylans extracted from different maize fiber sources. Food Hydrocoll. 2014, 39, 280-285. [CrossRef]

5. Izydorczyk, M.; Billiaderis, C. Cereal arabinoxylans: Advances in structure and physicochemical properties. Carbohydr. Polym. 1995, 28, 33-48. [CrossRef]

6. Niño-Medina, G.; Carvajal-Millan, E.; Rascon-Chu, A.; Marquez-Escalante, J.A.; Guerrero, V.; Salas-Muñoz, E. Feruloylated arabinoxylans and arabinoxylan gels: Structure, sources and applications. Phytochem. Rev. 2010, 9, 111-120. [CrossRef]

7. Delzenne, N.M.; Neyrinck, A.M.; Backhed, F.; Cani, P.D. Targeting gut microbiota in obesity: Effects of prebiotics and probiotics. Nat. Rev. Endocrinol. 2011, 7, 639-646. [CrossRef] [PubMed]

8. Grootaert, C.; van den Abbeele, P.; Marzorati, M.; Broekaert, W.F.; Courtin, C.M.; Delcour, J.A.; Verstraete, W.; Van de Wiele, T. Comparison of prebiotic effects of arabinoxylan oligosaccharides and inulin in a simulator of the human intestinal microbial ecosystem. FEMS Microbiol. Ecol. 2009, 69, 231-242. [CrossRef] [PubMed]

9. Carvajal-Millan, E.; Landillon, V.; Morel, M.-H.; Rouau, X.; Doublier, J.-L.; Micard, V. Arabinoxylan gels: Impact of the feruloylation degree on their structure and properties. Biomacromolecules 2005, 6, 309-317. [CrossRef] [PubMed]

10. González-Estrada, C.-S.M.; Carvajal-Millan, E.; Ascencio Valle, F.J.; Ragazzo-Sánchez, J.A.; Brown-Bojorquez, F.; Rascón-Chu, A. Covalently cross-linked arabinoxylans films for Debaryomyces hansenii entrapment. Molecules 2015, 20, 11373-11386.

11. Morales-Ortega, A.; Carvajal-Millan, E.; Brown-Bojorquez, F.; Rascón-Chu, A.; Torres-Chavez, P.; López-Franco, Y.; Lizardi-Mendoza, J.; Martínez-López, A.; Campa-Mada, A. Entrapment of probiotics in water extractable arabinoxylan gels: Rheological and microstructural characterization. Molecules 2014, 19, 3628-3637. [CrossRef] [PubMed] 
12. Amine, K.M.; Champagne, C.P.; Salmieri, S.; Britten, M.; St-Gelais, D.; Fustier, P.; Lacroix, M. Effect of palmitoylated alginate microencapsulation on viability of Bifidobacterium longum during freeze-drying. LWT Food Sci. Technol. 2014, 56, 111-117. [CrossRef]

13. Martínez-López, A.L.; Carvajal-Millan, E.; Micard, V.; Rascón-Chu, A.; Brown-Bojorquez, F.; Sotelo-Cruz, N.; López-Franco, Y.L.; Lizardi-Mendoza, J. In vitro degradation of covalently cross-linked arabinoxylan hydrogels by bifidobacteria. Carbohydr. Polym. 2016, 144, 76-82. [CrossRef] [PubMed]

14. Carvajal-Millan, E.; Rascón-Chu, A.; Márquez-Escalante, J.A. Method for Maize Gum Recovery from Alkaline Maize Wastewater. Mexican Patent 278,768, 7 September 2010.

15. Carvajal-Millan, E.; Rascón-Chu, A.; Márquez-Escalante, J.A.; Micard, V.; León, N.P.D.; Gardea, A. Maize bran gum: Extraction, characterization and functional properties. Carbohydr. Polym. 2007, 69, 280-285. [CrossRef]

16. Bradford, M. A rapid and sensitive method for the quantification of microgram quantities of protein utilizing the principle of protein-dye binding. Anal. Biochem. 1976, 72, 248-254. [CrossRef]

17. AOAC. Association of official analytical chemists. In Official Methods of Analysis of AOAC International, 17th ed.; AOAC International: Gaithersburg, MD, USA, 2002.

18. Flory, P.J.; Rehner, J. Statistical mechanics of cross-linked polymer networks II. Swelling. J. Chem. Phys. 1943, 11, 521. [CrossRef]

19. Peppas, N.A.; Merrill, E.W. Poly(vinyl alcohol) hydrogels: Reinforcement of radiation-crosslinked networks by crystallization. J. Polym. Sci. Polym. Chem. Ed. 1976, 14, 441-457. [CrossRef]

20. Saulnier, L.; Guillon, F.; Sado, P.E.; Chateigner-Boutin, A.L.; Rouau, X. Plant Cell Wall Polysaccharides in Storage Organs: Xylans (Food Applications); Elsevier: Amsterdam, The Netherlands, 2013.

21. Morales-Ortega, A.; Carvajal-Millan, E.; López-Franco, Y.; Rascón-Chu, A.; Lizardi-Mendoza, J.; Torres-Chavez, P.; Campa-Mada, A. Characterization of water extractable arabinoxylans from a spring wheat flour: Rheological properties and microstructure. Molecules 2013, 18, 8417-8428. [CrossRef] [PubMed]

22. Martínez-López, A.L.; Carvajal-Millan, E.; Rascón-Chu, A.; Márquez-Escalante, J.; Martínez-Robinson, K. Gels of ferulated arabinoxylans extracted from nixtamalized and non-nixtamalized maize bran: Rheological and structural characteristics. CyTA 2013, 11, 22-28. [CrossRef]

23. Berlanga-Reyes, C.M.; Carvajal-Millán, E.; Caire Juvera, G.; Rascón-Chu, A.; Marquez-Escalante, J.A.; Luisa, M.-L.A. Laccase induced maize bran arabinoxylan gels: Structural and rheological properties. Food Sci. Biotechnol. 2009, 18, 1027-1029.

24. Martínez-López, A.L.; Carvajal-Millan, E.; Lizardi-Mendoza, J.; López-Franco, Y.L.; Rascón-Chu, A.; Salas-Muñoz, E.; Barron, C.; Micard, V. The peroxidase $/ \mathrm{H}_{2} \mathrm{O}_{2}$ system as a free radical-generating agent for gelling maize bran arabinoxylans: Rheological and structural properties. Molecules 2011, 16, 8410-8418. [CrossRef] [PubMed]

25. Niño-Medina, G.; Carvajal-Millan, E.; Lizardi, J.; Rascón-Chu, A.; Gardea, A. Feruloylated arabinoxylans recovered from low-value maize by-products. In Encyclopedia of Polymer Research; Jones, C.E., Ed.; Nova Science Publishers, Inc.: New York, NY, USA, 2011; pp. 1401-1416.

26. Schell, M.A.; Karmirantzou, M.; Snel, B.; Vilanova, D.; Berger, B.; Pessi, G.; Zwahlen, M.C.; Desiere, F.; Bork, P.; Delley, M.; et al. The genome sequence of Bifidobacterium longum reflects its adaptation to the human gastrointestinal tract. Proc. Natl. Acad. Sci. USA 2002, 99, 14422-14427. [CrossRef] [PubMed]

27. Bezkorovainy, A.; Miller-Catchpole, R. Biochemistry and Physiology of Bifidobacteria; CRS Press: Boca Raton, FL, USA, 1989; p. 233.

28. Ekhart, P.F.; Van Der Saag, H.; Possemiers, S.; Van Den Abbeele, P.; Van De Wiele, T.; Neyrinck, A.M.; Nelly Delzenne, N.M.; Cani, P.C. Arabinoxylans for Modulating the Barrier Function of the Intestinal Surface. U.S. Patent 8465788 B2, 18 June 2013.

29. Crittenden, R.; Laitila, A.; Forssell, P.; Mättö, J.; Saarela, M.; Mattila-Sandholm, T.; Myllärinen, P. Adhesion of Bifidobacteria to Granular Starch and Its Implications in Probiotic Technologies. Appl. Environ. Microbiol. 2001, 67, 3469-3475. [CrossRef] [PubMed]

(c) 2016 by the authors; licensee MDPI, Basel, Switzerland. This article is an open access article distributed under the terms and conditions of the Creative Commons Attribution (CC-BY) license (http://creativecommons.org/licenses/by/4.0/). 